BMJ Nutrition,

Prevention \& Health

\section{Assessment, outcomes and implications of multiple anthropometric deficits in children}

To cite: Kundan I, Nair R, Kulkarni S, et al. Assessment, outcomes and implications of multiple anthropometric deficits in children. $B M J$ Nutrition, Prevention \& Health 2021:4:e000233. doi:10.1136/ bmjnph-2021-000233

${ }^{1}$ Department of Women and Child Development, Government of Maharashtra, Mumbai, Maharashtra, India

${ }^{2}$ Maharashtra Office, UNICEF, Mumbai, India

${ }^{3}$ RJMC Health and Nutrition Mission, Department of Women and Child Development, Government of Maharashtra, Mumbai, Maharashtra, India ${ }^{4}$ Public Health, Government of Maharashtra, Mumbai, Maharashtra, India

Correspondence to Shashwat Kulkarni, RJMC Health and Nutrition Mission, Department of Women and Child Development, Government of Maharashtra, Mumbai 400001, India; mail@shashwatk.com and

Dr Mrudula Phadke; drmapaa@yahoo.com

Received 21 January 2021 Accepted 14 May 2021 Published Online First 7 June 2021

Check for updates

(c) Author(s) (or their employer(s)) 2021. Re-use permitted under CC BY-NC. No commercial re-use. See rights and permissions. Published by BMJ.

\section{ABSTRACT}

Background Malnutrition in children is widely prevalent around the world. It has been observed that malnourished children with multiple anthropometric deficits have higher mortality. However, adequate studies are not available on the outcome and recovery of these children.

Nandurbar, a tribal district from Maharashtra, India, shows high prevalence of all three forms of malnutrition, often occurring simultaneously. A project previously undertaken in Nandurbar from July 2014 to June 2016 studied the effect of various therapeutic feeds in treatment of children with uncomplicated severe acute malnutrition (SAM). In this study, we analyse secondary data from it to correlate effects of stunting, wasting and underweight on treatment recovery.

Methods Analysis was done on 5979 children with SAM using linear and logistic regression on R software for recovery rates and weight gain in children with SAM with single versus multiple anthropometric deficits, their relation to age, sex, and recovery from severe stunting by gain in height.

Results The mean age of children was 35 months and $53.1 \%$ of the children were males. $2346(39.2 \%)$ children recovered at the end of the 8-week treatment. 454 (7.6\%) had single anthropometric deficit (SAM only), $3164(52.9 \%)$ had two anthropometric deficits (SAM and severe underweight (SUW)) and 2355 (39.4\%) children had three anthropometric deficits (SAM, SUW and severe stunting). Out of the 5979 children with SAM, only 52 $(0.9 \%)$ of children were not underweight (severe or moderate).

$44.94 \%$ of children with SAM who were severely stunted recovered, compared with $35.52 \%$ of children who were not $(p<0.001)$. After controlling for confounders, severe stunting was found to increase the odds of recovery by 1.49. Severely stunted children with SAM also showed faster recovery and weight gain by 1.93 days $(p<0.012)$ and $0.29 \mathrm{~g} / \mathrm{kg} /$ day $(p<0.001)$, respectively. Recovery was higher in females and younger age group. Recovery was also found to depend on the therapeutic feed, with children receiving medical nutrition therapy showing better recovery for severely stunted children.

Conclusion Our findings corroborate previous literature that stunting is a way for the body to deal with chronic stress of nutritional deprivation and provides a survival advantage to a child.

\section{What this paper adds}

\section{What is already known}

- Multiple forms of malnutrition, namely stunting, wasting and underweight often occur simultaneously in children and lead to additional risks of mortality and morbidity.

- Studies currently do not exist on the recovery characteristics of children with multiple forms of malnutrition

\section{What are the new findings}

- Secondary data of a treatment intervention for children with uncomplicated severe acute malnutrition were analysed.

- Severely wasted children with multiple anthropometric deficits had faster and higher percentage of recovery as compared to children with only severe wasting.

- Severe stunting was found to increase the odds of recovery by 1.49 , recovery time by 1.93 days, weight gain rate by $0.29 \mathrm{~g} / \mathrm{kg} /$ day.

\section{What do the new findings imply}

- Reductive adaptation, seen as a method for the body to deal with the chronic stress of nutrient deprivation leads to stunted children responding better to therapeutic foods.

- Even as stunting imparts a survival advantage to a severely undernourished child, there exist several long-term consequences of stunting such as cognitive impairment and lower wages.

\section{INTRODUCTION}

Malnutrition imposes major threat to child survival. Forty-five per cent of mortality in children under 5 years of age has malnutrition as a contributory factor. ${ }^{1}$ Wasting, stunting and underweight are three major facets of undernutrition. As per data collected by National Family Health Survey - 4 (NFHS-4), India has $38.4 \%$ stunting in children under 5 years, $21 \%$ wasting and $35.8 \%$ underweight. This is even higher in the district of Nandurbar, from where this data arises. Stunting in Nandurbar is seen in $49.7 \%$ of children, while wasting 
in $40.4 \%$ and underweight in $57 \%$ of children under 5 years. $^{2}$

Children with severe acute malnutrition (SAM) require early diagnosis and treatment. They are managed mainly in two ways. The first is for children who have SAM with oedema or integrated management of neonatal and childhood illness (IMNCI) complications or failure of appetite. Such children need admission to a nutrition rehabilitation centre (NRC) or to similar hospital setting. The second intervention is for children with SAM with good appetite and without any complications. These children can be managed in the community using energy dense specific therapeutic foods with micronutrients or medical nutrition therapy (MNT), antibiotics, deworming and so on.

Many children with SAM have multiple anthropometric deficits, such as wasting accompanying stunting, or wasting, stunting and underweight occurring simultaneously. ${ }^{3}$ However, data are scant on the recovery of such children with multiple anthropometric deficits. In this study, we examined the effect of multiple anthropometric deficits, such as being stunted and being underweight, on the recovery characteristics of severely wasted children who were given therapeutic foods of various types.

\section{Methodology}

This study involved collection and analysis of a part of secondary data from a larger study that involved screening, detection and treatment of children with SAM between 6 months to 59 months of age. In that study, children were screened by health workers in the tribal district of Nandurbar during from June 2014 to July 2016. The identification of SAM was made as per WHO criteria of Weight-for-Height Z-Scores of less than -3 SD. Children with SAM who had appetite failure or complications by IMNCI criteria like oedema, respiratory infections, breathlessness, diarrhoea, dehydration, convulsions and so on were referred for admission to an NRC. Remaining children were enrolled in the community management of acute malnutrition programme in various villages through Government of Maharashtra's Integrated Child Development Services scheme. Such enrolled children were given three types of energy dense therapeutic foods. These were: (1) ready to use therapeutic food (RUTF), that is, commercially made MNT, (2) locally prepared RUTF, also known as SF and (3) amylase rich food (ARF) with micronutrients. All three types of feeds had nearly similar composition, were energy dense, had micronutrients, peanut butter, milk

\begin{tabular}{llll}
\hline \multicolumn{3}{l}{ Table 1 Distribution of recovery characteristics } & \\
\hline $\begin{array}{l}\text { Count and } \\
\text { percentage of } \\
\text { recovery }\end{array}$ & Not cured & Cured & Total \\
\hline Count & 3633 & 2346 & 5979 \\
\hline Percentage & $60.76 \%$ & $39.24 \%$ & $100 \%$ \\
\hline
\end{tabular}

\begin{tabular}{llll} 
Table 2 & Distribution of sex & & \\
\hline Distribution of sex & Females & Males & Total \\
\hline Count & 2802 & 3177 & 5979 \\
Percentage & $46.86 \%$ & $53.13 \%$ & $100 \%$ \\
\hline
\end{tabular}

powder, oil and sugar giving calories 420-500 kcals per $100 \mathrm{~g}$ approximately. Amylase rich food had sprouted green gram and wheat (data published separately).$^{45}$ In the study, recovery (or cured) was defined as children who achieve weight for height >-2 SD on WHO growth charts during treatment, otherwise child was termed as 'not cured'. Data from all three groups were clubbed together as the main aim of this study was to analyse the difference in recovery characteristics of children with single or multiple anthropometric deficits. This analysis, hence only pertains to uncomplicated children who were treated in the community.

We studied the secondary data further. Data were cleaned and baselines were obtained. Children were classified 'severely stunted' if they had height for age less than $-3 \mathrm{SD}$, and 'severely underweight (SUW)' if they had weight for age scores less than -3 SD on WHO growth charts. Data were tested for variability across clusters and the levels of malnutrition was observed to be uniformly distributed across them. Defaulters were equally distributed among severely stunted and not severely stunted as well as underweight and non-underweight groups. The variables of interest (ie, stunting and underweight) were then tested for correlations with age, sex, and treatment groups. These were controlled for.

The recovery rates of children were higher in the MNT treatment groups $(52.8 \%)$ as compared with the ARF $(44.8 \%)$ and $\mathrm{SF}(43.5 \%)$ treatment groups. Further, as the randomisation of treatment was not stratified by stunting status in the original study, we found that stunting was correlated with factors such as the treatment arm. Therefore, it was necessary to control for these confounders. Regression models were then set-up and control variables were introduced to isolate the effect of stunting and underweight on recovery time and percentages.

Only children who completed the treatment (per protocol and not intention-to-treat) were included as cure and recovery time could not be calculated for defaulters. Thus, data of 5979 children were available for study.

Table 3 Distribution of multiple anthropometric deficits

\begin{tabular}{lll}
\hline $\begin{array}{l}\text { Multiple } \\
\text { anthropometric } \\
\text { deficits }\end{array}$ & $\begin{array}{l}\text { Severely } \\
\text { stunted }\end{array}$ & $\begin{array}{l}\text { Not severely } \\
\text { stunted }\end{array}$ \\
\hline $\begin{array}{l}\text { Severely } \\
\text { underweight }\end{array}$ & $2355(39.4 \%)$ & $3164(52.9 \%)$ \\
$\begin{array}{l}\text { Not severely } \\
\text { underweight }\end{array}$ & $6(0.1 \%)$ & $454(7.6 \%)$ \\
\hline
\end{tabular}




\begin{tabular}{|c|c|c|c|}
\hline $\begin{array}{l}\text { Recovery by } \\
\text { stunting status }\end{array}$ & Not cured & Cured & Total \\
\hline $\begin{array}{l}\text { Not severely } \\
\text { stunted }\end{array}$ & $64.48 \%$ & $35.52 \%$ & $100 \%$ \\
\hline Severely stunted & $55.06 \%$ & $44.94 \%$ & $100 \%$ \\
\hline Difference & & $-9.42 \%{ }^{* * *}$ & \\
\hline
\end{tabular}

Significant codes $<0.001$ : “***); $<0.01$ : ‘**’; $<0.05$ : ‘*”.

\section{Regression specifications}

Linear models were used to estimate the effect of stunting and underweight on recovery time and weight gain. Logistic regression was run for the effect of per cent recovery. Difference-in-difference models were tested to see whether the found differences in recovery time and percentages differ between males and females, or by age.

\section{Weight gain and recovery time}

Weight gain and recovery time used linear regression models with the following specification:

$$
\begin{aligned}
& \mathrm{Y}=\beta_{0}+\beta_{1} * \mathrm{D}_{\text {stunted }}+\beta_{2} * \mathrm{D}_{\text {underweight }}+\beta_{3} * \mathrm{D}_{\text {sex }}+ \\
& \beta_{4} * \text { Age }+\beta_{5} * \mathrm{D}_{\mathrm{MNT}}+\beta_{6} * \mathrm{D}_{\mathrm{SF}}+\epsilon
\end{aligned}
$$

Where,

Yis either:

1. The weight gain in grams per day per kilogram of weight of the child OR

2. The time taken for the child to recover,

$\mathrm{D}_{\text {stunted }}$ is a dummy variable that takes 1 if the child is severely stunted and 0 otherwise,

$\mathrm{D}_{\text {underweight }}$ is a dummy variable that takes 1 if the child is underweight and 0 otherwise,

Control variables:

$\mathrm{D}_{\text {sex }}$ is a dummy variable that takes 1 if the child is male and 0 if female,

Ageis the age of the child in months,

$\mathrm{D}_{\mathrm{MNT}}$ and $\mathrm{D}_{\mathrm{SF}}$ are treatment group controls for the different treatment arms (MNT, SF and ARF) that take 1 if the child is in that control group, and 0 if not.

\section{Per cent recovery}

As the outcome variable (cured or not) is binary a logistic regression was run, with the following specification:

$$
\begin{aligned}
& \operatorname{logit}(\mathrm{Y})=\beta_{0}+\beta_{1} * \mathrm{D}_{\text {stunted }}+\beta_{2} * \mathrm{D}_{\text {underweight }}+\beta_{3} * \mathrm{D}_{\text {sex }}+ \\
& \beta_{4} * \text { Age }+\beta_{5} * \mathrm{D}_{\mathrm{MNT}}+\beta_{6} * \mathrm{D}_{\mathrm{SF}}+\epsilon
\end{aligned}
$$

Where,

Yis an outcome variable taking 1 if the child has recovered and 0 if not,
$\mathrm{D}_{\text {stunted }}$ is a dummy variable that take 1 if the child is severely stunted and 0 otherwise,

$D_{\text {underweight }}$ is a dummy variable that take 1 if the child is severely underweight and 0 otherwise.

Control variables:

$\mathrm{D}_{\text {sex }}$ is a dummy variable that take 1 if the child is male and 0 if female,

Ageis the age of the child in months,

$\mathrm{D}_{\mathrm{MNT}}$ and $\mathrm{D}_{\mathrm{SF}}$ are treatment group controls for the different treatment arms (MNT, SF and ARF) that take 1 if the child is in that control group, and 0 if not,

\section{Ethics and approvals}

The larger study, whose data this paper studied, was approved by the ethics committee of Haffkine Institute, Mumbai, and the trial was registered under clinical trial registry of India with identifier CTR/2014/09/004958. Data safety monitoring board and community advisory board were constituted and were informed periodically about adverse events if any. Part of this data and the results are published. ${ }^{45}$

A total of $60.76 \%$ children did not recover at the end of treatment for 8 weeks while $39.24 \%$ recovered. This is depicted in table 1 .

\section{RESULTS}

Out of 5979 children studied, $53.13 \%$ were males, indicating male preponderance. This is depicted in table 2. This is higher than the Census 2011 where $51.44 \%$ of children 0-6 years were boys. Although it is generally assumed that females in India are ignored by the family and hence more likely to become SAM, the percentage of males was found to be more. This indicates that either tribals in Nandurbar are not discriminatory towards female children or that more males were brought to the health facility or were identified in mass household screening.

Table 3 presents the distribution of multiple anthropometric deficits in our data. Further, only 52 (8.7\%) children were found to not be stunted or underweight (severe or moderate). This indicates that wasting and severely stunting is almost always accompanied by underweight.

\section{Recovery characteristics of multiple anthropometric deficits}

As depicted in table 4, Recovery rate was $35.52 \%$ in children with SAM who were not severely stunted while the recovery rate was $44.94 \%$ in children with SAM who were severely stunted. The difference between the two was found to be statistically significant $(p<0.001)$. After controlling for confounders, severe stunting was found

\begin{tabular}{llllllll}
\hline Table 5 & Effect of severe stunting and underweight on recovery adjusted for confounders \\
\hline & Intercept $\left(\beta_{0}\right)$ & Severe stunting $\left(\beta_{1}\right)$ & Severe underweight $\left(\beta_{2}\right)$ & $\begin{array}{l}\text { Sex } \\
\left(\beta_{3}\right)\end{array}$ & $\begin{array}{l}\text { Age } \\
\left(\beta_{4}\right)\end{array}$ & $\begin{array}{l}\text { MNT } \\
\left(\beta_{5}\right)\end{array}$ & $\begin{array}{l}\text { SF } \\
\left(\beta_{6}\right)\end{array}$ \\
\hline & - & $1.490^{* * *}$ & 0.831 & $2.183^{* * *}$ & $0.817^{* * *}$ & $0.974^{* * *}$ & $0.763^{* *}$ \\
OR of recovery $(\mathrm{OR})$ & $<0.001$ & $<0.001$ & 0.102 & $<0.001$ & $<0.001$ & $<0.001$ & 0.009
\end{tabular}

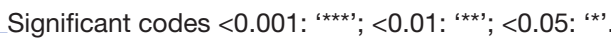




\begin{tabular}{|c|c|c|c|c|}
\hline $\begin{array}{l}\text { Recovery characteristics by } \\
\text { multiple deficits }\end{array}$ & $\begin{array}{l}\text { Severe stunted + SAM } \\
+ \text { SUW }\end{array}$ & SAM + SUW & Difference & $\begin{array}{l}\text { P value of } \\
\text { difference }\end{array}$ \\
\hline Recover time (days) & 37.6 days & 40.2 days & -2.6 days ${ }^{*}$ & 0.012 \\
\hline Weight gain g/kg/day & 2.720 & 2.235 & $0.485^{\star \star \star}$ & $<0.001$ \\
\hline
\end{tabular}

Significant codes $<0.001$ : “***); $<0.01$ : ‘**’; $<0.05$ : ‘*”.

to increase the odds of recovery by 1.49 . In other words, severely stunted children were found to be $48.97 \%$, more likely to recover than children not severely stunted. The results of this regression analysis, adjusted for confounders, are presented in table 5 .

Recovery time in children with SAM with severe stunting and SUW was 37.6 days while the same in children with SAM and SUW without severe stunting was 40.2 days. Difference in weight gain in these two groups was $0.485 \mathrm{~g} / \mathrm{kg} /$ day $(\mathrm{p}<0.001)$. This is depicted in table 6 .

After controlling for confounders, severe stunting was found to increase the weight gain of children with SAM by $0.288 \mathrm{~g} / \mathrm{kg} /$ day. Underweight was found to increase the weight gain of children with SAM by $0.422 \mathrm{~g} / \mathrm{kg} /$ day. The results of this regression analysis, adjusted for confounders, are presented in table 7. Similarly, controls were added, and regression was conducted for recovery time as well. Severe stunting was found to decrease the recovery time by 1.93 days. The results are presented in table 8 .

The effect of severe underweight and severe stunting on weight gain, by age is plotted in figure $1 \mathrm{~A}, \mathrm{~B}$. The effect of severe stunting on recovery time, by age is plotted in figure 1C. Please note that being underweight has no statistically significant effect on recovery time as can be seen in table 8 .

Severely stunted children with SAM showed a higher percentage of recovery, recovered in a lesser number of days and gained weight faster than the group not severely stunted (all values being statistically significant).

Distribution of multiple anthropometric deficits across sex is presented in table 9. As depicted in table 10, recovery rate in females was higher $(47.2 \%)$ compared with that in males $(42.5 \%)$, the difference being statistically significant. Even though more males were admitted to the intervention, and though more males were severely stunted, the recovery rate was seen to be significantly higher for females (both severely stunted and not severely stunted).

Among severely stunted children, those below 2 years were found in a higher proportion. Moreover, within an age category, fewer proportion of children are severely stunted, and this proportion decreases with age. This is presented in tables 11 and 12. The average age of children in our study was 35.03 months.

Age was found to affect the recovery rate, depicted in table 13. Children below 2 years show a higher percentage of recovery. Recovery rate from SAM in the first year was $73.29 \%$, gradually decreasing to $28.39 \%$ at $5-6$ years of age.

\section{Gain in height}

Gain in height, that is, recovery from severe stunting showed that $98.1 \%$ children remained severely stunted at discharge. After adding controls, the recovery rate from severe stunting was $3.75 \%$ only.

\section{DISCUSSION}

Anthropometric measurements are one of the important and easy ways of detecting malnutrition in the community and of estimation of the nutritional status of a population. Degrees of malnutrition are associated with increased risk of all-cause mortality and increased risk of death due to diarrhoea, pneumonia, and measles. ${ }^{6}$

It is now a proven fact that children with SAM have 9.4 times higher risk of death compared with normal children of that age. Wasted children often get severe infections many times more than normal children and may succumb. Wasting denotes acuteness of the onset of malnutrition. Stunting, on the other hand, is a chronic process of energy and micronutrient deficiency. Stunting also results in 4.1 times the increased risk of dying, although less than wasting. ${ }^{35}$ However, stunting is associated with delayed

Table 7 Effect of severe stunting and underweight on weight gain rate, adjusted for confounders

\begin{tabular}{lccccccc}
\hline & Intercept $\left(\beta_{0}\right)$ & Severe stunting $\left(\beta_{1}\right)$ & Severe underweight $\left(\beta_{2}\right)$ & $\begin{array}{l}\text { Sex } \\
\left(\beta_{3}\right)\end{array}$ & $\begin{array}{l}\text { Age } \\
\left(\beta_{4}\right)\end{array}$ & $\begin{array}{l}\text { MNT } \\
\left(\beta_{5}\right)\end{array}$ & $\begin{array}{l}\text { SF } \\
\left(\beta_{6}\right)\end{array}$ \\
\hline Estimate & $2.889^{\star \star *}$ & $0.288^{\star \star *}$ & $0.422^{\star \star *}$ & $-0.315^{\star \star *}$ & $-0.035^{\star \star *}$ & $1.013^{\star * *}$ & 0.087 \\
SE & 0.116 & 0.059 & 0.107 & 0.055 & 0.001 & 0.066 & 0.071 \\
P value & $<0.001$ & $<0.001$ & $<0.001$ & $<0.001$ & $<0.001$ & $<0.001$ & 0.222 \\
\hline
\end{tabular}

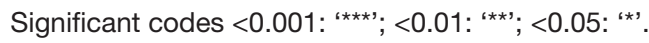


Table 8 Effect of stunting and underweight on recovery time with controls

\begin{tabular}{|c|c|c|c|c|c|c|c|}
\hline & Intercept $\left(\beta_{0}\right)$ & Severe stunting $\left(\beta_{1}\right)$ & Severe underweight $\left(\beta_{2}\right)$ & $\begin{array}{l}\text { Sex } \\
\left(\beta_{3}\right)\end{array}$ & $\begin{array}{l}\text { Age } \\
\left(\beta_{4}\right)\end{array}$ & $\begin{array}{l}\text { MNT } \\
\left(\beta_{5}\right)\end{array}$ & $\begin{array}{l}\text { SF } \\
\left(\beta_{6}\right)\end{array}$ \\
\hline Estimate & $42.692^{\star \star \star}$ & $-1.926^{\star \star \star}$ & -0.813 & $1.587^{\star *}$ & $0.114^{\star \star \star}$ & $-9.379^{\star \star \star}$ & $-6.854^{\star \star \star}$ \\
\hline$P$ value & $<0.001$ & $<0.001$ & 0.421 & 0.004 & $<0.001$ & $<0.001$ & $<0.001$ \\
\hline
\end{tabular}

Significant codes $<0.001$ : “***; $<0.01$ : “**’; $<0.05$ : ‘*’.

child development, lower school achievement, reducing work and earning capacity in adulthood, increase in adult non-communicable diseases, difficult labour in women and low birth weight in progeny. ${ }^{3}$

It is thought that stunting is the body mechanism to deal with the chronic stress of nutrient deprivation. It has been termed as reductive adaptation. ${ }^{7}$ Underweight like stunting is a form of chronic undernutrition measured as weight-for-age, indicative growth faltering. These anthropometric indicators describe the various dimensions of child growth in particular linear growth (bones), fat and muscle. The aetiology of malnutrition is complex, as nutritional status is the product of numerous interactions between food intake, disease, metabolism, immunity, and endocrine system.

Our primary study was undertaken on the second group, that is, children with SAM who were given three types of energy-dense foods in the community. Recovery rates, defaulters and deaths were the endpoints. As an offshoot of this primary study, we analysed data from 5979 children from the viewpoint of outcome of children with single and multiple anthropometric deficits, relation to age and sex. Recovery from stunting was also studied. Following important observations have been noted.

We first observe that out of 5979 children of SAM without complications, only $52(0.9 \%)$ of the children with SAM were not underweight. Further, there were only six children who have severe stunting but were not severely underweight. This indicates that wasting is almost always accompanied by underweight. Our findings support previous studies that suggest that the term 'WaSt' (Wasting and Stunting) be used instead of multiple anthropometric deficits.

Our second observations pertain to the recovery of the children with severe stunting. We find that children with SAM show higher rates of recovery $(\mathrm{OR}=1.49)$, show higher rate weight gain $(0.29 \mathrm{~g} / \mathrm{kg} /$ day $)$ and recover faster (1.93 days). However, we did not observe a significant gain in height, that is, recovery from severe stunting showed that $98.1 \%$ children remained severely stunted at discharge. After adding controls, the recovery rate from severe stunting was $3.75 \%$ only. This could be due to a short-term of follow-up.

Third, we observe that recovery rates were higher in females $(47.2 \%)$ compared with that in males $(42.5 \%)$, the difference being statistically significant. Further, age also affected the recovery rate. The recovery rate from
SAM in the first year was $73.29 \%$, gradually decreasing to $28.39 \%$ at $5-6$ years of age.

Various studies have reported that wasting is more common in the younger age group and females. Large sex differences in nutritional status and mortality are found mostly in South-Asia. They are associated with the family composition and differential food allocation by sex and birth order, with girls of birth order $2+$ being at higher risk. Wasting is more typical in younger children (6-29 months) and stunting in older children (30-59 months), although both could occur at any age ${ }^{9}$ In sub-Saharan Africa, sex differences in the prevalence of malnutrition are small, if not negligible. ${ }^{10}$ No such effects have been documented so far in Africa. In a study by Shashank Kumbarahalli, stunting was seen to be more prevalent in males $(40.1 \%)$ than in females $(35.9 \%) .{ }^{11}$ Study from Senegal showed that boys were more stunted than girls in infancy and up to 39 months. In a study in Yemen stunting was found significantly more among boys aged 2-5 years compared with $<2$ years while wasting, underweight and Composite Index of Anthropometric Failure (CIAF) were significantly higher among girls aged 2-5 years compared with $<2$ years. ${ }^{12} 13$ Most authors attribute these sex differences in nutritional status to biological differences in morbidity between boys and girls in early life. Indeed, perinatal outcomes are often less favourable for boys than for girls, even in developed countries. Moreover, boys have higher birth weights than girls and grow faster during infancy, resulting in greater energy needs. In a large cohort study in Cebu, Philippines, boys had a higher incidence of stunting than girls did from birth to 14 months and a higher prevalence from 6 to 18 months of age. ${ }^{13}$

Effects of multiple deficits were studied by McDonald et al. ${ }^{14}$ They found higher mortality in children with multiple deficits than those with single deficits. The risk of all-cause mortality was elevated among children with one, two and three anthropometric deficits. Compared with children with no deficits, the mortality HRs were 3.4 (95\% CI: 2.6 to 4.3) among children who were stunted and underweight but not wasted; 4.7 (95\% CI: 3.1 to 7.1) in those who were wasted and underweight but not stunted; and 12.3 (95\% CI: 7.7 to 19.6) in those who were stunted, wasted and underweight. Stunting is an indicator of linear growth retardation that results from failure to receive adequate nutrition over a long period or recurrent infections. It may be exacerbated by recurrent and 


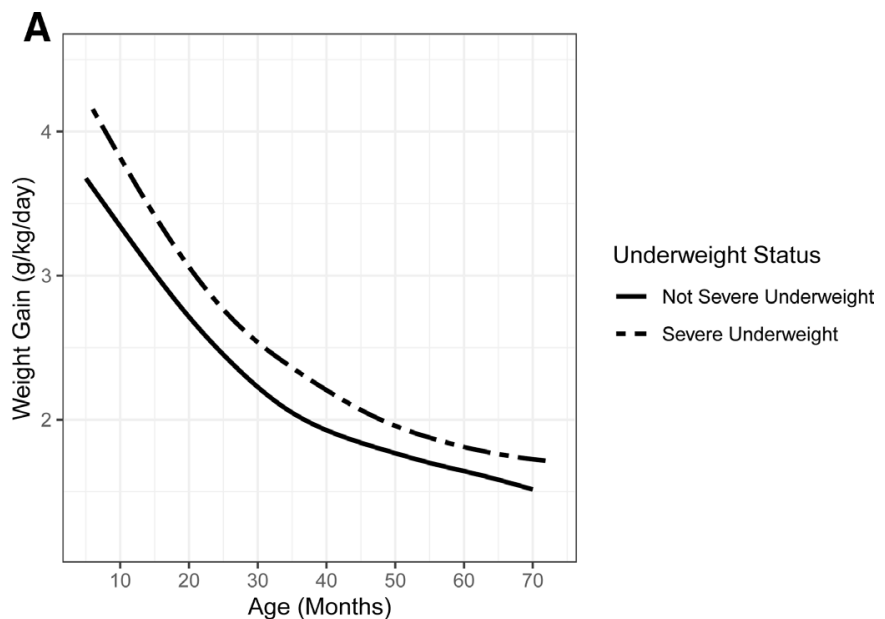

B

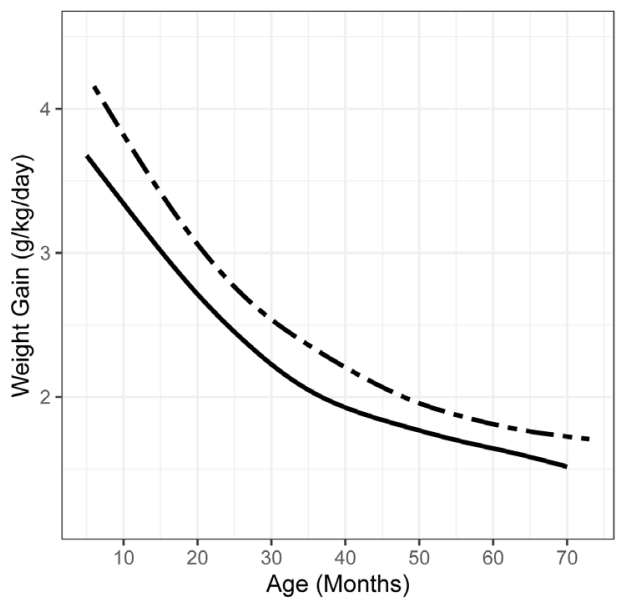

Stunting Status

- Not Severly Stunted

- - Severly Stunted

C

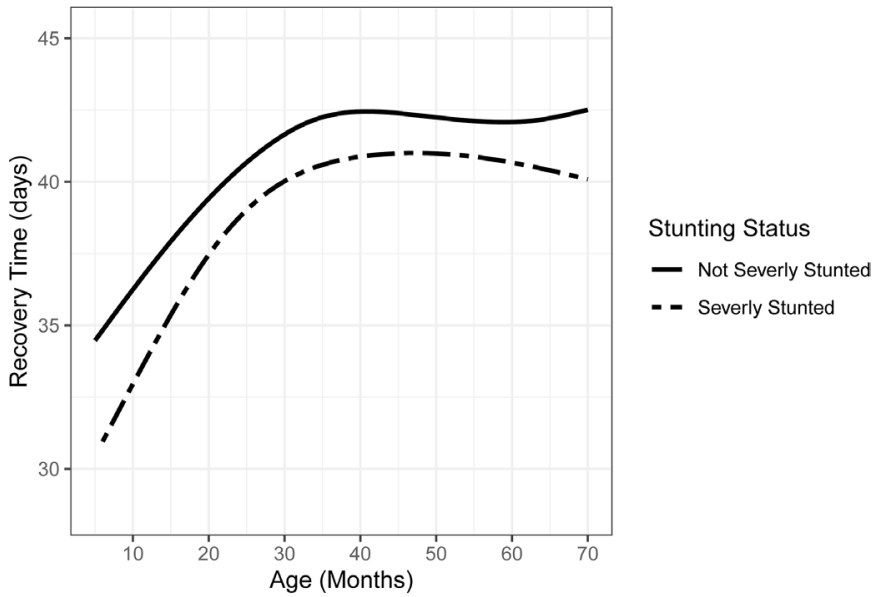

Figure 1 (A) Effect of underweight on weight gain, (B) effect of severe stunting on weight gain, $(\mathrm{C})$ effect of severe stunting on recovery time.

chronic illness. It is an indicator of past growth failure. It is associated with a number of long-term factors including chronic insufficient nutrient intake, frequent infection, sustained inappropriate feeding practices, poor water and sanitation practices and poverty-the potential causes of stunting range from poor hygiene to inadequacy in food intake as well as repeated infections. Even through
Table 9 Distribution of multiple anthropometric deficits across sex

\begin{tabular}{llll}
\hline $\begin{array}{l}\text { Distribution } \\
\text { of stunting by } \\
\text { sex }\end{array}$ & Females & Males & Total \\
\hline $\begin{array}{l}\text { Severely } \\
\text { stunted and } \\
\text { severe acute } \\
\text { malnutrition }\end{array}$ & $1001(42.3 \%)$ & $1360(57.7 \%)$ & $2361(100 \%)$ \\
$\begin{array}{l}\text { Severe acute } \\
\text { malnutrition } \\
\text { but not } \\
\text { severely } \\
\text { stunted }\end{array}$ & $1801(49.7 \%)$ & $1817(51.3 \%)$ & $3618(100 \%)$ \\
\hline \begin{tabular}{l} 
Total \\
\hline
\end{tabular} & 2802 & & \\
\hline
\end{tabular}

stunting is complex as an entity, it may reflect several aetiologies, particularly a diet that is poor, unbalanced diet and an insufficient intake of vitamin and micronutrients. Stunted children show low levels of amino acids as well as vitamin D. In one study, ${ }^{14}$ all nine essential amino acids were found to be significantly lower in the stunted children compared with controls (height-for-age (HAZ) $<-2$ standard deviation (SD)). Additionally, the serum concentrations of conditionally essential amino acids (arginine, glycine and glutamine) were significantly low in stunted children who also were found to have low levels of non-essential amino acids (asparagine, glutamate and serine) and six sphingolipids, as well as altered serum glycerophospholipid concentrations.

Adimasu $e t$ al studied effect of stunting on hospitalised children with SAM and found that many factors like associated pneumonia, stunting immunisation increased the recovery time and stay in the hospital. ${ }^{15}$

There are no reports on the recovery time of stunted and wasted children without complications and managed in the community. This is the first report that suggests that the management of children with multiple anthropometric deficits can give rewarding results. Our study highlights the fact that in uncomplicated non-oedematous children with SAM, stunting proved to be an advantage. Number of stunted children recovered was more,

Table 10 Recovery across stunting status and sex

\begin{tabular}{|c|c|c|c|}
\hline $\begin{array}{l}\text { Distribution } \\
\text { of recovery } \\
\text { across sex }\end{array}$ & Females & Males & Difference \\
\hline All & $47.2 \%$ & $42.5 \%$ & $4.7 \%$ *** \\
\hline \multicolumn{4}{|c|}{ By stunting status } \\
\hline $\begin{array}{l}\text { Severely } \\
\text { stunted }\end{array}$ & $55.20 \%$ & $48 \%$ & $7.20 \%$ * \\
\hline $\begin{array}{l}\text { Not severely } \\
\text { stunted }\end{array}$ & $42.80 \%$ & $38.40 \%$ & $4.40 \% *$ \\
\hline Difference & $12.40 \%$ *** & $9.60 \%$ *** & $2.80 \%$ \\
\hline
\end{tabular}

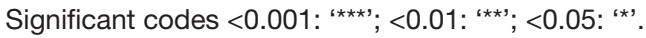




\begin{tabular}{|c|c|c|c|}
\hline $\begin{array}{l}\text { Distribution } \\
\text { of stunting } \\
\text { by age }\end{array}$ & Below 2 years & 2 to 6 years & Total \\
\hline $\begin{array}{l}\text { Not severely } \\
\text { stunted }\end{array}$ & 1193 (32.97\%) & 2425 (67.03\%) & 3618 (100\%) \\
\hline $\begin{array}{l}\text { Severely } \\
\text { stunted }\end{array}$ & 1107 (46.88\%) & $1254(53.12 \%)$ & 2361 (100\%) \\
\hline Total & 2300 & 3679 & 5979 \\
\hline
\end{tabular}

recovery time was less and they showed better weight gain than children with SAM without stunting. Children with severely stunted growth experience increased mortality as well as morbidity from infections, most commonly diarrhoea or pneumonia, but also meningitis, tuberculosis, sepsis and hepatitis, which suggests a generalised immune disorder. The interplay of poor nutrition and frequent infection leads to a vicious cycle of worsening nutritional status and increasing susceptibility to infection. Nutritional status is impaired further by infections through reduced appetite, reduced intestinal absorption, heightened catabolism and diversion of nutrients towards immune response, away from growth. In turn, the risk of infection increases due to undernutrition by its negative impact on the epithelial barrier function and altered immune response. ${ }^{116}$

A limitation of our study is that the data used in this study are secondary measures of quality of the data such the technical error of measurement is not available. Further, the data pertains to a community with high levels of socio-economic and nutritional deprivation and the results found in this data may not fully translate in better socio-economically placed communities.

Our data reveal an important finding that if children with SAM and stunting are treated with therapeutic food, micronutrients and antibiotics, they improve and recover from SAM better. This could be explained by the fact that these children were detected by active screening procedure at a time when they had not developed complications and had a good appetite, their bodies were well adapted to the stress of chronic energy deficiency. When therapeutic food was given, their small bodies requiring less energy responded well by weight gain. However, an increase in height and recovery from stunting was seen in a few children as they were probably not followed for a longer period.

\begin{tabular}{lcc}
\hline $\begin{array}{l}\text { Table } 12 \\
\begin{array}{l}\text { Distribution of stunting } \\
\text { within age categories }\end{array}\end{array}$ & Below 2 years & $\begin{array}{l}\text { 2 to } \mathbf{6} \\
\text { years }\end{array}$ \\
\hline Not severely stunted & $51.87 \%$ & $65.91 \%$ \\
\hline Severely stunted & $48.13 \%$ & $34.09 \%$ \\
\hline Total & $100 \%$ & $100 \%$ \\
\hline
\end{tabular}

Table 13 Percentage recovery across age categories

\begin{tabular}{|c|c|c|c|}
\hline $\begin{array}{l}\text { Percentage } \\
\text { recovery by age }\end{array}$ & 2 to 6 & Below 2 & Difference \\
\hline All & $37.2 \%$ & $57 \%$ & $19.8 \%$ *** \\
\hline \multicolumn{4}{|c|}{ By stunting status } \\
\hline Severely stunted & $42.90 \%$ & $60.50 \%$ & $-17.60 \%$ *** \\
\hline $\begin{array}{l}\text { Not severely } \\
\text { stunted }\end{array}$ & $34.30 \%$ & $53.70 \%$ & $-19.40 \%$ *** \\
\hline Difference & $8.60 \%$ ** & $6.80 \%$ ** & $1.80 \%$ \\
\hline
\end{tabular}

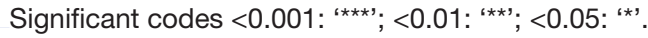

Stunting is a mirror and reflection of malnutrition in the community, indicating the level of nutritional deprivation in the community. Population studies often used stunting as proxies for economic and social deprivation. ${ }^{16}{ }^{17}$ At the individual level, however, it posited as reductive adaptation to the child, seen as a way for the body to deal with a chronic lack of nutrition. Our findings, which see improved recovery characteristics in stunted children, corroborate previous literature positing that stunting offers survival advantage to nutritionally deprived children. ${ }^{718} 19$

Contributors IK was involved in conceptualisation of the study and making the data available. RN was involved in conceptualisation, was in-charge of the project, was involved in collection of data and giving technical inputs. SK was involved in conceptualisation, design of the study, preparation and analysis of the data and writing the manuscript. $A D$ was involved in the collection of the data, working in the field, giving technical inputs and clinical comments. RJ gave technical inputs and clinical comments. MP was involved in conceptualisation, writing the manuscript, designing the study, technical and clinical contributions to the study and leading the conduct of this study.

Funding The authors have not declared a specific grant for this research from any funding agency in the public, commercial or not-for-profit sectors.

Competing interests None declared.

Patient consent for publication Not required.

Provenance and peer review Not commissioned; externally peer reviewed.

Data availability statement Data are available upon reasonable request. Data are the property of Government of Maharashtra, India, and can be shared on reasonable request.

Open access This is an open access article distributed in accordance with the Creative Commons Attribution Non Commercial (CC BY-NC 4.0) license, which permits others to distribute, remix, adapt, build upon this work non-commercially, and license their derivative works on different terms, provided the original work is properly cited, appropriate credit is given, any changes made indicated, and the use is non-commercial. See: http://creativecommons.org/licenses/by-nc/4.0/.

ORCID iDs

Shashwat Kulkarni http://orcid.org/0000-0002-6349-6846

Mrudula Phadke http://orcid.org/0000-0002-1138-6899

\section{REFERENCES}

1 Black RE, Allen LH, Bhutta ZA, et al. Maternal and child undernutrition: global and regional exposures and health consequences. Lancet 2008;371:243-60.

2 National Family Health Survey 2014-15 (NFHS-4). International Institute for population sciences (IIPS), 2015. Available: http://rchiips. org/nfhs/nfhs4.shtml

3 de Onis M, Branca F. Childhood stunting: a global perspective: childhood stunting: a global perspective. Matern Child Nutr 2016;12:12-26. 
4 Bhoye R, Phadke M, Aguayo V. Domiciliary treatment of severe acute malnutrition. Int $J$ Nutr 2017;2:1-5.

5 Sujata S, Mrudula P, Raji N, et al. Safety, tolerability, efficacy and logistics of administration of three types of therapeutic feeds to children with severe acute malnutrition (SAM). IJN 2018;3:10-15.

6 Phadke M, Nair R, Menon P, et al. Evolution of anthropometry in malnutrition. IJN 2020;4:25-35.

7 Golden $\mathrm{MH}$. Evolution of nutritional management of acute malnutrition. Indian Pediatr 2010;47:667-78.

8 Myatt M, Khara T, Schoenbuchner S, et al. Children who are both wasted and stunted are also underweight and have a high risk of death: a descriptive epidemiology of multiple anthropometric deficits using data from 51 countries. Arch Public Health 2018;76:28.

9 Victora CG. The association between wasting and stunting: an international perspective. J Nutr 1992;122:1105-10.

10 Garenne M, Myatt M, Khara T, et al. Concurrent wasting and stunting among under-five children in Niakhar, Senegal. Matern Child Nutr 2019;15:e12736.

11 Jawaregowda SK, Angadi MM. Gender differences in nutritional status among under five children in rural areas of Bijapur district, Karnataka, India. Int J Community Med Public Health 2017;2:506-9.

12 Bork KA, Diallo A. Boys are more stunted than girls from early infancy to 3 years of age in rural Senegal. J Nutr 2017;147:940-7.
13 Al-Sadeeq AH, Bukair AZ, M. Al-Saqladi A-W. Assessment of undernutrition using Composite Index of Anthropometric Failure among children aged $<5$ years in rural Yemen. East Mediterr Health $J$ 2018;24:1119-26.

14 McDonald CM, Olofin I, Flaxman S, et al. The effect of multiple anthropometric deficits on child mortality: meta-analysis of individual data in 10 prospective studies from developing countries. Am J Clin Nutr 2013;97:896-901.

15 Adimasu M, Sebsibie G, Abebe F, et al. Recovery time from severe acute malnutrition and associated factors among under-5 children in Yekatit 12 Hospital, Addis Ababa, Ethiopia: a retrospective cohort study. Epidemiol Health 2020;42:e2020003.

16 Black RE, Victora CG, Walker SP, et al. Maternal and child undernutrition and overweight in low-income and middle-income countries. Lancet 2013;382:427-51.

17 M'Kaibi FK, Steyn NP, Ochola SA, et al. The relationship between agricultural biodiversity, dietary diversity, household food security, and stunting of children in rural Kenya. Food Sci Nutr 2017;5:243-54.

18 Elizabeth KE. Nutrition \& Child Development. Paras Medical Publisher, 1998.

19 O AGa, Hay RW, Picou DI. Protein-energy malnutrition. London: Edward Arnold (Publishers) Ltd, 1977. https://www.cabdirect.org/ cabdirect/abstract/19782900462 